This site uses cookies. More info $\boldsymbol{\bigotimes}$ Close By continuing to browse the site you are agreeing to our use of cookies. Find out more here Close

Analysis

\title{
Judging nudging: can nudging improve population health?
}

BMJ 2011; 342 doi: https://doi.org/10.1136/bmj.d228 (Published 25 January 2011) Cite this as: BMJ

2011;342:d228

- Article

- $\underline{\text { Related content }}$

- Metrics

- Responses

- Peer review

-

Theresa M Marteau, director ${ }^{1}$, David Ogilvie, clinical investigator scientist ${ }^{2}$, Martin Roland, professor of health services research ${ }^{1}$, Marc Suhrcke, professor of public health economics ${ }^{3}$, Michael P Kelly, director4

\section{Author affiliations}

Correspondence to: T M Marteau theresa.marteau@medschl.cam.ac.uk

Accepted 9 January 2011

Nudging has captured the imagination of the public, researchers, and policy makers as a way of changing human behaviour, with both the UK and US governments embracing it. Theresa Marteau and colleagues ask whether the concept stands up to scientific scrutiny

If people didn't smoke, drank less, ate healthier diets and were more active, the huge burden of chronic diseases such as cancer, heart disease, and type 2 diabetes would be much reduced.1 The prospect of being able to nudge populations into changing their behaviour has generated great interest among policymakers worldwide, including the UK government.2 We explore what nudging is and assess the prospect of nudging our way to a healthier population.

\section{Understanding behaviour change}

Most people value their health yet persist in behaving in ways that undermine it. This can reflect a deliberate act by individuals who happen at different moments in time to value other things in life more highly than their health. It can also reflect a non-deliberate act. This gap between values and behaviour can be understood by using a dual process model in which human behaviour is shaped by two systems. 3 The first is a reflective, goal oriented system driven by our values and intentions. It requires cognitive capacity or thinking space, which is limited. Many traditional approaches to health promotion depend on engaging this system. Often based on providing information, they are designed to alter beliefs and attitudes, motivate people with the prospect of future benefits, or help them develop self regulatory skills. At best, these approaches have been modestly effective in changing behaviour.4

The second is an automatic, affective system that requires little or no cognitive engagement, being driven by immediate feelings and triggered by our environments. Despite wishing to lose weight, for example, we still buy the chocolate bar displayed by the checkout till. Such environmental cues combine with the power of immediate and certain pleasure over larger, less certain and more distant rewards to make unhealthy behaviour more likely. This suggests an approach to behaviour change that focuses on altering environmental cues to prompt healthier 
behaviour. Such an approach is readily embraced by advertisers and retailers and, increasingly, by public health specialists. 5 Nudging mainly operates through this automatic, affective system.

\section{What is nudging?}

The term "nudge" was first used in a book of the same title to describe "any aspect of the choice architecture that alters people's behaviour in a predictable way without forbidding any options or significantly changing their economic incentives." 6 It is exemplified by a simple intervention that substantially increased the amount that people saved for their retirement: an opt-in system in which people had to make a positive choice to set aside savings from their salaries was replaced by an opt-out system in which savings were made by default.7

The original definition of nudging excludes legislation, regulation, and interventions that alter economic incentives. Aside from these exclusions, nudging could include a wide variety of approaches to altering social or physical environments to make certain behaviours more likely. These might include providing information about what others are doing ("social norm feedback") framed to make healthy behaviours more salient, changing the defaults that surround the serving of food and drinks, or altering the layout of buildings to cue physical activity (table $\Downarrow)$. However, there is no precise, operational definition of nudging. This may reflect a reality-namely, that nudging is at best a fuzzy set8 intended to draw attention to the role of social and physical environments in shaping our behaviour and not to inform a scientific taxonomy of behaviour change interventions.

Examples of nudging and regulating actions

View this table:

- View popup

- View inline

Nudging is not new. It builds on psychological and sociological theory dating back over a century that shows how environments shape and constrain human behaviour9 1011 -often far more than we like to believe.12 Its novelty lies in two features. Firstly, it draws on behavioural economics and social psychology to explain why people behave in ways that deviate from rationality as defined by classical economics. 6 Secondly, it is embedded in libertarian paternalism, a political philosophy in which people's choices are actively guided in their best interests but they remain at liberty to behave differently.

The appeal of nudging is self evident: it proposes a set of seemingly simple, low cost solutions that do not require legislation and can be applied to a wide array of problems arising from our behaviour. The absence of legislation holds particular appeal for governments and others wanting a smaller role for the state in shaping the behaviour of its citizens.

\section{Does nudging work?}

Nudging certainly works. Shaping environments to cue certain behaviours is extremely effective, unfortunately often to the detriment of our health. The ready availability of foods that are packaged, presented, and engineered to stimulate our automatic, affective system has led us to consume more than we need13 - consumption that is further primed by advertising.14 The doubling in alcohol consumption in young people over the past 50 years is attributed in part to its marketing and ready availability, 15 and the design of many neighbourhoods supports car driving over walking or cycling.16

Nudging can certainly trigger behaviours that worsen our health, but can it also be used to cue behaviours that improve it? There are various descriptions of nudges being used to change behaviour to improve health outcomes (table $\Uparrow$ ). For example, putting yellow duct tape across the width of supermarket trolleys with a sign requesting shoppers to place fruit and vegetables in front of the line doubled fruit and vegetable purchasing,17 and placing fruit by the cash register increased the amount of fruit bought by school children at lunchtime by 
70\%.18 Providing information on the healthy behaviour of others (social norm feedback) is the most extensively studied form of nudging, particularly in the context of alcohol consumption among students. Interventions have been delivered using a range of methods including social marketing campaigns and giving feedback in groups and to individuals, delivered in letters or through the internet.19 While there is evidence of effectiveness for internet feedback, there is little for the others.

To date, few nudging interventions have been evaluated for their effectiveness in changing behaviour in general populations and none, to our knowledge, has been evaluated for its ability to achieve sustained change of the kind needed to improve health in the long term. Dolan and colleagues suggested that nudging is likely to offer good value for money, 20 but this cannot be assumed because the cost effectiveness of nudges has not been evaluated. Some environmental changes are potentially very expensive, and individualised feedback of social norms may also be costly.

It may, of course, be misguided to expect evidence of such outcomes from individual nudges: more realistically, cumulative nudges in a wide range of contexts may be required, within enabling legislative and policy environments. Effective nudging may require legislation, either to implement healthy nudges (such as displaying fruit at checkouts) or to prevent unhealthy nudges from industry (such as food advertising aimed at children). Voluntary agreements can sometimes be modestly effective. For example, daily salt consumption in the UK has been reduced by $0.9 \mathrm{~g}$ per person as a result of agreements by food manufacturers and led by the Food Standards Agency, although these were reinforced by a threat of legislation.21 This achievement contrasts with reductions of $5 \mathrm{~g}$ per person in Finland and Japan after legislation.22 In general, self regulation by the food, alcohol, and tobacco industries has historically been less effective than legislation as a means to improve population health.23 2425

At present, the evidence to support the view that nudging alone can improve population health is weak. We therefore need both primary research and synthesis of existing evidence to examine the effectiveness and acceptability of nudging interventions. Given the diversity of interventions involved, evidence synthesis should place different types of nudges within a more comprehensive taxonomy of approaches to behaviour change. Furthermore, this work should not be limited to asking what works but should adopt a more realist position (what works, for whom, in what circumstances, and for how long?),26 comparing the effects of different types of nudges in different regulatory environments. Nudging may help to promote a culture that is accepting of legislation to promote health, suggesting a role for historical and anthropological critiques in understanding its possible contribution to altering long term behaviour trends in populations. The effect sizes obtained from nudging in different regulatory environments could also be compared with those of other approaches such as regulating pricing and advertising, with outcomes including effects on health inequalities and cost effectiveness. We could then begin to judge what nudging contributes to the existing policy toolbox for improving population health and reducing inequalities.

\section{Could nudging be harmful?}

As with any intervention, a public health strategy based on nudging has the potential to generate harms as well as benefits. Direct harm may arise from perverse response to nudges. For example, labelling foods as healthy, or making healthier side dishes the default, can lead to a "halo" effect resulting in underestimation of energy content and consequent excess consumption. 27 In one study participants estimated that a hamburger contained 697 calories when it was presented alone but 642 calories when it was presented with three celery sticks, an effect that was greatest among people concerned about managing their weight.28 These findings illustrate why evaluations must include the capacity to identify paradoxical or unexpected effects of seemingly benign nudges.29

In The Strategy of Preventive Medicine, Rose contrasted two approaches to improving population health.30 The first involves targeting people at high risk-for example, by identifying and treating individuals with high blood 
pressure to reduce their risk of stroke. The second involves shifting the population distribution of a risk factor-for example, by reducing population salt intake-and therefore mean blood pressure-with the aim of reducing the overall incidence of stroke. Although these two strategies are not mutually exclusive, there is growing evidence that whole population approaches may be more effective both in improving population health and in reducing health inequalities, 3132 with strategies that target only high risk individuals tending to widen health inequalities. 3334

While nudging relates more closely to whole population approaches to disease prevention, indirect harm might arise if an emphasis on nudging resulted in neglect of population level interventions that were potentially more effective. Recent reports highlight the continuing importance of tackling the economic and regulatory environments in the areas of alcohol, obesity, and tobacco control. For example, regulations to limit the availability of alcohol are more effective than voluntary agreements with the alcohol industry in reducing alcohol related harm35; a review of measures to tackle obesity has concluded that pricing interventions and regulation of food labelling and marketing to children are likely to produce the largest health gains in the shortest times36; and the balance of evidence suggests that increasing the price of tobacco may be more effective in reducing smoking among adults on lower incomes and in manual occupations than among those with higher incomes and nonmanual occupations, which cannot be said for other approaches such as printing health warnings on cigarette packets.37

\section{Conclusions}

Nudge and similar recent popular texts have stimulated policymakers to think about altering environments to change behaviour. These developments are to be welcomed. Evidence to support the effectiveness of nudging as a means to improve population health and reduce health inequalities is, however, weak. This reflects absence of evidence as well as evidence of little or no effect.

Without regulation to limit the potent effects of unhealthy nudges in existing environments shaped largely by industry, nudging towards healthier behaviour may struggle to make much impression on the scale and distribution of behaviour change needed to improve population health to the level required to reduce the burden of chronic disease in the UK and beyond.

\section{Notes}

Cite this as: $B M J 2011 ; 342: \mathrm{d} 228$

\section{Footnotes}

- Contributors and sources: This article was prepared following a review of the literature and discussions with colleagues (notably Simon Cohn, Simon Griffin, Susan Jebb, Ann Louise Kinmonth, Tom Ling, and Daniel Zizzo) in preparation for a programme of empirical reviews of the effects of altering choice architecture to change behaviour to improve population health. TMM had the idea for the paper, with all authors contributing to the literature review, analysis and drafting. TMM is guarantor.

- Funding: Department of Health policy research programme (107/0001_Policy Research Unit in Behaviour and Health). The views expressed are not necessarily those of the department.

- Competing interests: All authors have completed the unified competing interest form at www.icmje.org/coi_disclosure.pdf (available on request from the corresponding author) and declare no support from any organisation for the submitted work; no financial relationships with any organisation that 
might have an interest in the submitted work in the previous three years; and no other relationships or activities that could appear to have influenced the submitted work.

- Provenance and peer review: Not commissioned; peer reviewed.

\section{References}

1. $\triangleleft$ WHO. Global health risks: mortality and burden of disease attributable to selected major risks. WHO, 2009. Google Scholar

2. «Department of Health. Healthy lives, healthy people: Our strategy for public health in England. DH, 2010. Google Scholar

3. «Strack F, Deutsch R. Reflective and impulsive determinants of social behavior. Pers Soc Psychol Rev2004;8:220-47. Find Full Text Abstract/FREE Full Text Google Scholar

4. $\mathrm{WHORegional} \mathrm{Committee} \mathrm{for} \mathrm{Europe.} \mathrm{Behaviour} \mathrm{change} \mathrm{strategies} \mathrm{and} \mathrm{health:} \mathrm{the} \mathrm{role} \mathrm{of} \mathrm{health} \mathrm{systems.} \mathrm{WHO,}$ 2008. Google Scholar

5. «Beaglehole R, Horton R. Chronic diseases: global action must match global evidence. Lancet2010;376:1619-21. Find Full Text CrossRef PubMed Web of Science Google Scholar

6. «Thaler RH, Sunstein C. Nudge: improving decisions about health, wealth, and happiness. Yale University Press, 2008. Google Scholar

7. $₫$ Thaler RH, Benartzi S. Save more tomorrow (TM): using behavioral economics to increase employee saving. J Political Econ2004;112:S164-87. Find Full Text CrossRef Web of Science Google Scholar

8. «Zadeh LA. Fuzzy sets. Information and Contro/1965;8:338-9. Find Full Text CrossRef Web of Science Google Scholar

9. $\longleftrightarrow$ Thorndike E. Education psychology: briefer course. Routledge, 1913. Google Scholar

10. $\triangleleft$ Ross L, Nisbett R. The person and the situation. McGraw-Hill, 1991. Google Scholar

11. «Durkheim E. Suicide: a study in sociology. Routledge \& Kegan Paul, 1952[1897]. Google Scholar

12. 4 Ross L. The intuitive psychologist and his shortcomings: distortions in the attribution process. In: Berkowitz L, ed. Advances in experimental social psychology. Academic Press, 1977:174-221. Google Scholar

13. $\triangleleft$ Ruhm C. Understanding overeating and obesity. NBER Working Paper No 16149. National Bureau of Economic Research, 2010. Google Scholar

14. 4 Harris JL, Bargh JA, Brownell KD. Priming effects of television food advertising on eating behavior. Health Psycho/2009;28:404-13. Find Full Text CrossRef PubMed Web of Science Google Scholar

15. $\longleftrightarrow$ House of Commons Health Committee. Alcohol: first report of session 2009-10. London: House of Commons, 2010. Google Scholar

16. «Sallis JF, Bowles HR, Bauman A, Ainsworth BE, Bull FC, Craig CL, et al. Neighborhood environments and physical activity among adults in 11 countries. Am J Prev Med2009;36(6):484-90. Find Full Text CrossRef PubMed Web of Science Google Scholar

17. «Grocery cart choice architecture, 2010. http://nudges.org/2010/08/13/grocery-cart-choice-architecture/ . Google Scholar

18. + Just D, Wansink B. Smarter lunchrooms: using behavioral economics to improve meal selection. Choices2009;29(3). www.choicesmagazine.org/magazine/article.php?article=87. Google Scholar

19. «Moreira MT, Smith LA, Foxcroft D. Social norms interventions to reduce alcohol misuse in university or college students. Cochrane Database Syst Rev2009(3):CD006748. Google Scholar

20. «Dolan P, Hallsworth M, Halpern D, King D, Vlaev I. MINDSPACE: influencing behaviour through public policy. Institute for Government, Cabinet Office, 2010. Google Scholar

21. «Food Standards Agency. Salt reduction targets. FSA, 2009. Google Scholar

22. «Cappuccio FP, Capewell S. How to cut down salt intake in populations. Heart2010;96:1863-64. Find Full Text FREE Full Text Google Scholar 
23. «Sharma LL, Teret SP, Brownell KD. The food industry and self-regulation: standards to promote success and to avoid public health failures. Am J Public Health2010;100:240-6. Find Full Text CrossRef PubMed Web of Science Google Scholar

24. $\triangleleft$ Anderson P. Global alcohol policy and the alcohol industry. Curr Opin Psychiatry2009;22:253-7. Find Full Text CrossRef PubMed Web of Science Google Scholar

25. $\triangleleft$ ASH. The smoke-filled room: how Big Tobacco influences health policy in the UK. ASH, 2010. Google Scholar

26. «Pawson R, Tilley N. Realistic evaluation. London: Sage, 1997. Google Scholar

27. «Wansink B, Chandon P. Can "low-fat" nutrition labels lead to obesity? J Marketing Res2006;43:605-17. Find Full Text CrossRef Web of Science Google Scholar

28. «Chernev A. The dieter's paradox. J Consumer Psychology2010. doi:10.1016/j.jcps.2010.08.002. Google Scholar

29. «Petticrew M. Presumed innocent: why we need systematic reviews of social policies. Am J Prev Med2003;24:2-3. Find Full Text CrossRef PubMed Web of Science Google Scholar

30. $«$ Rose G. The strategy of preventive medicine. Oxford University Press, 1992. Google Scholar

31. «Emberson J, Whincup P, Morris R, Walker M, Ebrahim S. Evaluating the impact of population and high-risk strategies for the primary prevention of cardiovascular disease. Eur Heart J2004;25:484-91. Find Full Text Abstract/FREE Full Text Google Scholar

32. + Capewell S, Ford ES, Croft JB, Critchley JA, Greenlund KJ, Labarthe DR. Cardiovascular risk factor trends and potential for reducing coronary heart disease mortality in the United States of America. Bull World Health Organ2010;88:120-30. Find Full Text CrossRef PubMed Web of Science Google Scholar

33. «Hart JT. The inverse care law. Lancet 1971;i:405-12. Google Scholar

34. «Capewell S, Graham H. Will cardiovascular disease prevention widen health inequalities? PLoS Med2010;7:e1000320. Find Full Text CrossRef PubMed Google Scholar

35. $«$ NICE. Alcohol-use disorders: preventing the development of hazardous and harmful drinking: NICE Public Health Guidance 24. NICE, 2010. Google Scholar

36. $₫$ Cecchini M, Sassi F, Lauer JA, Lee YY, Guajardo-Barron V, Chisholm D. Tackling of unhealthy diets, physical inactivity, and obesity: health effects and cost-effectiveness. Lancet2010;376:1775-84. Find Full Text CrossRef PubMed Web of Science Google Scholar

37. «Thomas S, Fayter D, Misso K, Ogilvie D, Petticrew M, Sowden A, et al. Population tobacco control interventions and their effects on social inequalities in smoking: systematic review. Tob Control2008;17:230-7. Find Full Text Abstract/FREE Full Text $\underline{\text { Google Scholar }}$

View Abstract

\section{Other content recommended for you,}

Telehealth for patients at high risk of cardiovascular disease: pragmatic randomised controlled trial

Chris Salisbury et al., The BMJ

Associations of pet ownership with biomarkers of ageing: population based cohort study

G David Batty et al., The BMJ

Psychological distress in relation to site specific cancer mortality: pooling of unpublished data from 16 prospective cohort studies

G David Batty et al., The BMJ

Education and coronary heart disease: mendelian randomisation study
Primary Care Must Lead on Population Health

Theodore Long et al., Medscape

"Greening" Your Practice

David B. Wallinga et al., Medscape

Geisinger Experience Implementing Precision Medicine Spurs New Effort to Help Others Do the Same

GenomeWeb

UK Workshops on Synthetic Biology Reveal

Fascination, Worries

GenomeWeb

Many UK cancers blamed on lifestyle 
Incidence, clinical management, and mortality risk following self harm among children and adolescents: cohort study in primary care Catharine Morgan et al., The BMJ

Powered by

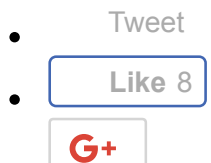

- G+

\section{Article tools}

2 responses

- ש゙Respond to this article

- BPrint

- Alerts \& updates

\section{Article alerts}

Please note: your email address is provided to the journal, which may use this information for marketing purposes.

\section{Log in or register:}

Username *

Password *

Log in

$\underline{\text { Register for alerts }}$

(1) If you have registered for alerts, you should use your registered email address as your username - Q Citation tools

\section{Download this article to citation manager}

Marteau Theresa M, Ogilvie David, Roland Martin, Suhrcke Marc, Kelly Michael P. Judging nudging: can nudging improve population health? BMJ 2011; 342 :d228

- BibTeX (win \& mac)

Download

- EndNote (tagged)

Download

- EndNote 8 (xml)

Download

- RefWorks Tagged (win \& mac)

- RIS (win only)

- Medlars

\section{Help}

If you are unable to import citations, please contact technical support for your product directly (links go to external sites): 
- EndNote

- ProCite

- Reference Manager

- RefWorks

- Zotero

- Request permissions

- Euthor citation

- Articles by Theresa M Marteau

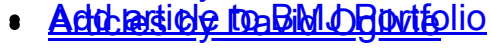

- Articles by Martin Roland

Email Ang Marc Suhrcke

- Articles by Michael P Kelly.

\section{Forward this page}

Thank you for your interest in spreading the word about The BMJ.

NOTE: We only request your email address so that the person you are recommending the page to knows that you wanted them to see it, and that it is not junk mail. We do not capture any email address.

\section{Username * \\ Your Email * \\ Send To *}

You are going to email the following Judging nudging: can nudging improve population health?

Your Personal Message

\section{Topics}

- Health promotion

- Cardiovascular medicine

- Diabetes

- Diet

- Metabolic disorders

more

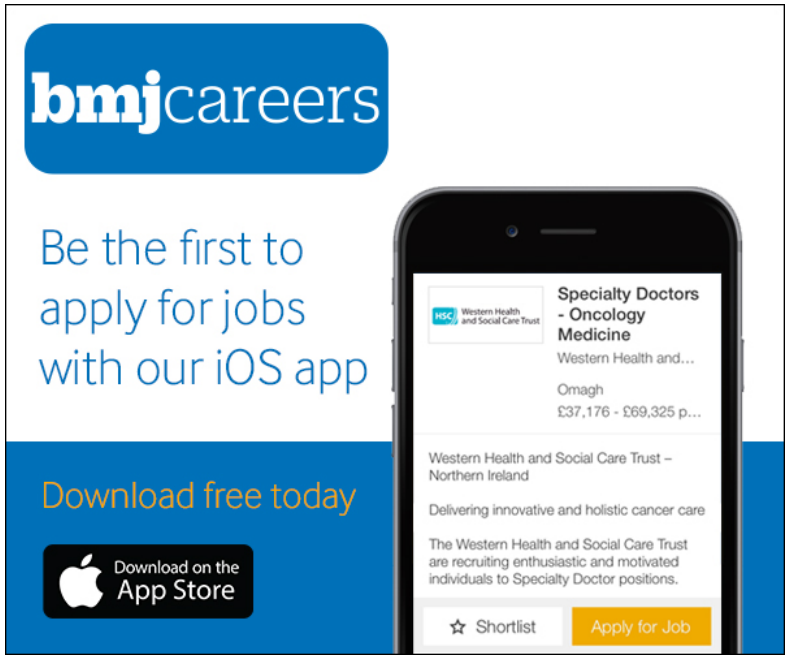




\section{Altmetric}

Who is talking about this article?

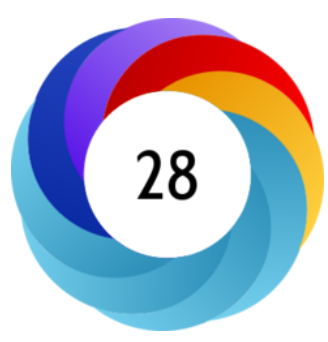

$\underline{\text { See more details }}$
Picked up by 1 news outlets

Blogged by 1

Referenced in 1 policy sources

Tweeted by 14

On 1 Facebook pages

467 readers on Mendeley

3 readers on CiteULike

A) Check for updates

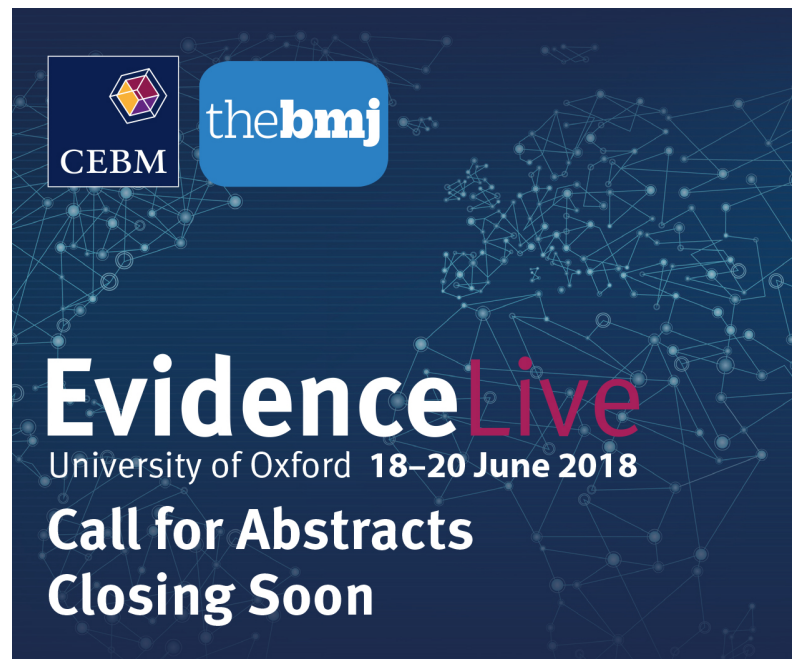

\section{This week's poll}

\section{Do you use WhatsApp for work?}

Yes

No

I don't use WhatsApp at all

Vote

View Results

$\underline{\text { Read related article }}$

See previous polls

- UK jobs

- International jobs

Sunderland GP Alliance: GP opportunities University Hospitals of Leicester NHS Trust: Consultant Breast Radiologist EPIC Workforce Development: General Practice Recruitment Event

East Lancashire Hospitals NHS Trust: Consultant in Palliative Medicine Brighton and Sussex University Hospitals NHS Trust: Consultant in Acute Medicine x 2 posts View more 
Back to top 